\title{
Heterocyst and Nitrogenase Development in Anabaena cylindrica
}

\author{
By S. BRADLEY AND N. G. CARR \\ Department of Biochemistry, University of Liverpool, P.O. Box I47, Liverpool L69 3BX
}

(Received 4 March 1976)

\begin{abstract}
SUMMARY
The differentiation of filaments of a continuous culture of Anabaena cylindrica after removal of fixed nitrogen has been examined. Rapid development of proheterocysts $(4.5 \mathrm{~h})$ and mature heterocysts $(14 \mathrm{~h})$ in an ordered sequence was observed ; the development of the latter was concomitant with the onset of nitrogenase activity. Commitment times of $2 \cdot 3 \mathrm{~h}$ (proheterocyst) and $5 \cdot 0 \mathrm{~h}$ (heterocyst) were measured. Evidence is presented that shows that heterocyst development, rather than any product of heterocyst function in nitrogen fixation, is responsible for the imposition of the pattern of heterocysts in a filament of vegative cells. Both phycocyanin content and carbon dioxide fixation declined markedly throughout the filament during the early stages of heterocyst development, indicating that all the cells of the filament are involved in the initial stages of the differentiation process. Heterocysts do not evolve oxygen in the light, but do respire. Nitrogenase activity in isolated heterocysts and in intact filaments was stimulated by phosphoenolpyruvate, ATP and dichlorophenolindophenol-ascorbate.
\end{abstract}

\section{INTRODUCTION}

Heterocysts are morphologically distinct, functionally specialized cells which occur in an ordered sequence in filaments of many species of blue-green algae when they are grown in the absence of fixed nitrogen (Fay, 1973; Tydgi, 1975; Wolk, 1975). The current interest in these specialized prokaryotic cells has dual origins. The proposal that heterocysts are the location of nitrogen fixation, and the attempts to explain their characteristic features in terms of the known requirements of nitrogenase activity (Fay 'et al., 1968) attracted attention to heterocyst physiology. This has not been diminished by subsequent demonstrations that although heterocysts are a major site of nitrogen fixation, it can also occur under specific conditions in apparently undifferentiated cells of at least some blue-green algae (Wyatt \& Silvey, 1969; Stewart \& Lex, 1970). The differentiation of heterocysts from vegetative cells, and their imposition as a recurring pattern in Anabaena filaments of up to several hundred cells, make the formation of heterocysts an attractive model for developmental biology (Wilcox, Mitchison \& Smith, I975).

In examining the formation of heterocysts in Anabaena cylindrica advantage can be taken of the fact that ammonium ions, and to a lesser extent nitrate ions, suppress their development (Fogg, 1949). Removing ammonium ions from a culture of $A$. cylindrica initiates heterocyst formation. We have studied heterocyst development under continuous-culture conditions, in which the period of heterocyst formation occurs in a uniform population of organisms and is not subject to constraints imposed by an ageing culture. Some of the results have been reported previously in a preliminary form (Bradley \& Carr, I97I ; Carr \& Bradley, 1973). 


\section{METHODS}

Organism. Anabaena cylindrica $\mathrm{I} 403 / 2$ a was obtained from the Culture Collection of Algae and Protozoa, The Botany School, Cambridge. Stock cultures were maintained on growth medium plus $\mathrm{I} \cdot 5 \%$ (w/v) agar and kept in the laboratory, away from direct sunlight and sealed with Parafilm to prevent desiccation.

Growth. The mineral salt medium of Allen \& Arnon (I955), called minimal medium in this paper, was used for growth under nitrogen fixing conditions. Non-nitrogen fixing cultures were obtained by supplementing the medium with I mM-ammonium chloride. Cultures ( $100 \mathrm{ml}$ in $250 \mathrm{ml}$ conical flasks) were inoculated from agar slopes and incubated at $30{ }^{\circ} \mathrm{C}$ in a Gallenkamp orbital illuminated shaker under a steady flow of carbon dioxide. Larger quantities (IO l) were grown in flasks at $30{ }^{\circ} \mathrm{C}, 20 \mathrm{~cm}$ from three $40 \mathrm{~W}$ warm white fluorescent tubes, and gassed with air/carbon dioxide $(95: 5, \mathrm{v} / \mathrm{v})$.

Continuous cultures were grown in a continuous fermenter, model CF500, with 7.5 1 capacity (New Brunswick Scientific Co., New Brunswick, New Jersey, U.S.A.), modified to accommodate phototrophic micro-organisms. Illumination was provided by eight $60 \mathrm{~W}$ opal tubular bulbs enclosed in glass fingers located $5 \mathrm{~cm}$ from the growth vessel, which was immersed in a $30{ }^{\circ} \mathrm{C}$ bath. The culture was agitated by an impeller at $300 \mathrm{rev} . \mathrm{min}^{-1}$ and gassed with air/carbon dioxide $(95: 5, \mathrm{v} / \mathrm{v})$. Medium was introduced at a fixed rate and the culture volume was kept constant by a sensing probe that activated an outlet pump. Having established the generation time for the organism under these conditions, the inlet pump was adjusted to deliver the culture volume during the generation time. The ammonia medium was replaced by minimal medium by pumping the culture, under pressure, through a filter of glass wool. The organisms were washed off the filter by pumping the new medium into the apparatus in the reverse direction. A Biotec LP300 continuous-culture apparatus, volume I 1 , was also used to examine heterocyst development.

Estimation of heterocyst and proheterocyst frequency. The criteria for mature heterocyst formation were the presence of polar bodies on a rounded cell bounded by a thickened cell wall and in which the cytoplasm appeared paler and less granular than in the vegetative cell. A proheterocyst was a cell which had already altered from the characteristic squarerectangular shape to become larger and spherical, but, while it may have had a less-granular cytoplasm, did not possess polar bodies. The frequencies of these cell types were counted at $500 \times$ magnification; not less than $2.5 \times 10^{3}$ vegetative cells were examined on each occasion.

Isolation of heterocysts. Anabaena cylindrica was harvested at room temperature in an Alfa Laval continuous-flow centrifuge, and homogenized in 0.005 original vols of a buffer containing $60 \mathrm{~mm}$-Tris, $\mathrm{pH} 8.0,50 \mathrm{~mm}-\mathrm{mannitol}$ and $30 \mathrm{~mm}-\mathrm{EDTA}$. Lysozyme ( $\mathrm{I} \cdot 0 \mathrm{mg} \mathrm{ml}-1$ ) was added and incubated with stirring for $\mathrm{I} \mathrm{h}$ at $4{ }^{\circ} \mathrm{C}$, before the suspension was passed through a chilled French pressure cell at 400 to $800 \mathrm{lbf}^{-2}$, 20 vols buffer were added, and the suspension was homogenized and centrifuged for Io min at $1200 \mathrm{~g}$. The pellet was resuspended in 30 vols buffer and recentrifuged at $600 \mathrm{~g}$ for $15 \mathrm{~min}$. This procedure was repeated twice. The centrifugation was done at room temperature, but the solutions and the preparation were kept in ice, when possible.

A cell-free preparation of isolated heterocysts was obtained by extrusion, repeated three times, through a pre-cooled French pressure cell at 12000 to $16000 \mathrm{lbf}^{-2}$, followed by removal of unbroken heterocysts and debris by centrifuging at $30000 \mathrm{~g}$ for I h.

Enzyme measurements. Reduced pyridine nucleotide oxidase activity was measured by the decline in $E_{340}$ at $30^{\circ} \mathrm{C}$. The experimental cuvette contained $(\mu \mathrm{mol}): 2-(N-2$-hydroxyethylpiperazin- $N^{\prime}$-yl)ethanesulphonic acid (Hepes) buffer, pH 7·6, I20; NADH or NADPH, $0 \cdot 5$; 
and cell extract ( 2 to $3 \mathrm{mg}$ protein), in a total volume of $3.0 \mathrm{ml}$. Nitrogenase was measured by the acetylene-reduction technique. A suspension of organisms in growth medium was incubated in $15 \mathrm{ml}$ serum bottles at $30{ }^{\circ} \mathrm{C}$ for $30 \mathrm{~min}$ under the light source used for growth. The gas phase consisted of $10 \%$ acetylene and $0.5 \%$ carbon dioxide in argon, and the production of ethylene was detected in a Pye (model 104) gas-liquid chromatograph equipped with a hydrogen flame detector, a Porapak R column, and operated at $50{ }^{\circ} \mathrm{C}$. Each estimation was done in triplicate.

Protein. The colorimetric method of Layne (1957) was used after chlorophyll and carotenoids had been removed by extraction with hot acidic ethanol (Vernon \& Kamen, I953). Low protein concentrations were estimated by a microbiuret method (Itzhaki \& Gill, 1964).

Chlorophyll. The $E_{666}$ of an extract in acetone/water $(80: 20, \mathrm{v} / \mathrm{v})$ was determined, and the chlorophyll concentration was calculated using the factor $\epsilon=6.58 \times 10^{4}$.

Phycocyanin. Absorption spectra in vivo of suspensions of $A$. cylindrica were measured using a Perkin-Elmer spectrophotometer, model 356. Phycocyanin content was expressed as the ratio of the extinction maximum at $620 \mathrm{~nm}$ to that of chlorophyll at $665 \mathrm{~nm}$.

Oxygen exchange. The production by organisms of oxygen in the light, and respiratory oxygen uptake in the dark, were measured in an oxygen electrode assembly (Yellow Springs Instrument Co., Yellow Springs, Ohio, U.S.A.) using approximately $2.0 \mathrm{mg}$ dry wt organisms/ml growth medium. 3-(3,4-Dichlorophenyl)-I, I-dimethylurea (DCMU) was obtained from K \& K Laboratories, Plainview, New York, U.S.A.

Carbon dioxide fixation. A suspension of organisms ( $10 \mathrm{ml}$ ) was incubated in the light at $32{ }^{\circ} \mathrm{C}$ with sodium $\left[{ }^{14} \mathrm{C}\right]$ bicarbonate $\left(10 \mu \mathrm{mol} ; 0.5 \mu \mathrm{Ci} \mu \mathrm{mol}^{-1}\right)$. Organisms were collected on $\mathrm{I} \cdot 2 \mu \mathrm{m}$ Sartorius membrane filters, washed and dried at $65^{\circ} \mathrm{C}$; radioactivity was determined using a Nuclear Chicago gas flow counter.

\section{RESULTS}

\section{Heterocyst development}

The growth rate of $A$. cylindrica in continuous culture was greater ( $16.4 \mathrm{~h}$ generation time) in the presence of ammonia than under nitrogen-fixing conditions $(2 \mathrm{I} \cdot 6 \mathrm{~h}$ generation time). Chlorophyll content, protein content and dry weight of organisms per $\mathrm{ml}$ remained constant and were directly related to each other during heterocyst development in continuous culture. When heterocyst development was initiated by replacing ammonia-containing medium with minimal medium, growth ceased after $\mathrm{Io} h$ and recommenced 6 to $8 \mathrm{~h}$ later. The acquisition of proheterocysts, heterocysts and nitrogenase was observed over $40 \mathrm{~h}$ (Fig. I). Proheterocysts were first discerned $4.5 \mathrm{~h}$ after initiation, and reached a maximum of $8.5 \%$ of the total cells of the filament after $\mathrm{I} 6 \mathrm{~h}$. Mature heterocysts appeared $\mathrm{I} 4 \mathrm{~h}$ after initiation and reached a maximum frequency $(6.8 \%)$ after $32 \mathrm{~h}$. Nitrogenase activity developed concomitantly with mature heterocyst formation. The frequency of proheterocysts and mature heterocysts started to decline $20 \mathrm{~h}$ after initiation; at this stage, growth of the filament had recommenced.

Nitrogenase activity, measured in the intact filament, decreased with the decrease in heterocyst frequency. The maximum nitrogenase activity, recorded $32 \mathrm{~h}$ after initiation, decreased by approximately $40 \%$ during the next $\mathrm{r} 3 \mathrm{~h}$. The fall in nitrogenase activity and in heterocyst frequency was later partially reversed; both these variables oscillated with an amplitude of approximately 10 \% over a $20 \mathrm{~h}$ period in an otherwise steady-state continuous culture. A similar time-base of development was observed when the experiment was conducted on a smaller scale in the Biotec LP300 continuous-culture apparatus; in this case the responses were more reproducible and the results of several experiments are summarized 


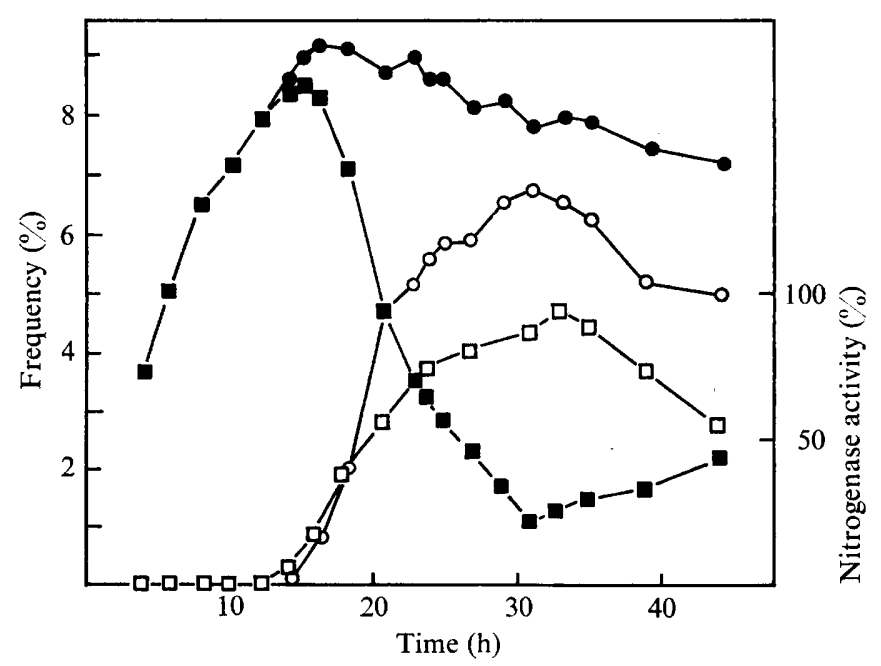

Fig. I. Time course of development in Anabaena cylindrica following ammonium ion deprivation. -, Total heterocyst frequency; $\mathbf{\square}$, proheterocyst frequency; $O$, heterocyst frequency; $\square$, nitrogenase activity, expressed as a percentage of the final activity.

\section{Table I. Timing of developmental processes of Anabaena cylindrica after deprivation of ammonia}

Cultures were grown in the Biotec LP300 continuous-culture apparatus, volume $\mathrm{I}$ 1. Results are the means of three experiments.

$\begin{array}{lcc} & \begin{array}{c}\text { Initial detection } \\ \text { (h) }\end{array} & \begin{array}{c}\text { Maximum } \\ \text { (h) }\end{array} \\ \text { Proheterocysts } & 5 \cdot 5 \pm 0 \cdot 5 & \text { I4 } \pm \text { I } \cdot 5 \\ \text { Heterocysts } & 14 \cdot 5 \pm \mathrm{I} \cdot 0 & 28 \pm 3 \\ \text { Nitrogenase activity } & 13 \cdot 5 \pm 2 \cdot 0 & 27 \pm 2\end{array}$

in Table I. The relationship between nitrogenase activity in intact filaments and the heterocyst frequency in those filaments is shown in Fig. 2. Heterocyst development was followed in batch culture under the same conditions as used in continuous culture (Fig. 3). After reaching $8 \%$, the heterocyst frequency fell to $6 \%$ during the latter part of the exponential-growth phase, and to $4 \%$ as the culture entered the stationary-growth phase.

The extent to which the process of heterocyst development was reversible was examined by removing samples (Io $\mathrm{ml}$ ) from the culture at various times after initiation. Ammonium chloride was added to the samples, to a final concentration of I $\mathrm{mM}$; and these were then grown, in batch culture, under the same conditions of light, temperature and gassing as had been used in the original continuous culture. The proportion of proheterocysts and heterocysts were counted after $24 \mathrm{~h}$ (Fig. 4). Proheterocysts developed in samples that had been initiated (i.e. deprived of ammonia) for $3 \mathrm{~h}$ and mature heterocysts in those initiated for $5 \mathrm{~h}$. By extrapolation, the commitment time for proheterocyst development was $2.3 \pm 0.5 \mathrm{~h}$, and for heterocyst development, $5 \cdot 0 \pm \mathrm{I} \cdot 0 \mathrm{~h}$; each value was the average of three separate experiments.

The effect of products of nitrogen fixation on heterocyst frequency was examined by developing heterocyst-containing filaments of $A$. cylindrica in continuous culture under an atmosphere of air/carbon dioxide $(95: 5, \mathrm{v} / \mathrm{v})$ or argon/carbon dioxide $(95: 5, \mathrm{v} / \mathrm{v})$. In both cases, during the first $20 \mathrm{~h}$ of development there was a rapid increase in the total number of 


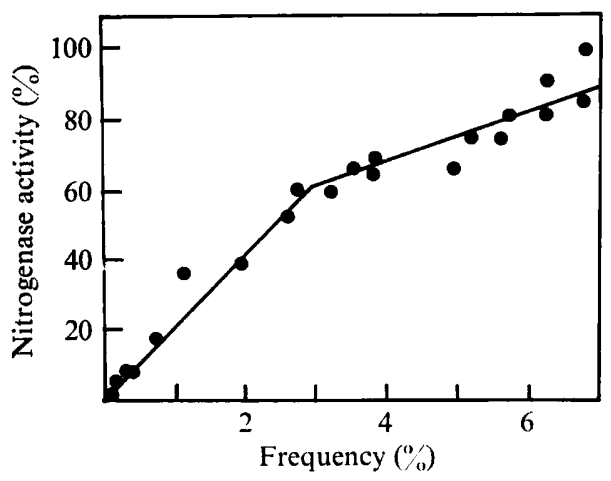

Fig. 2

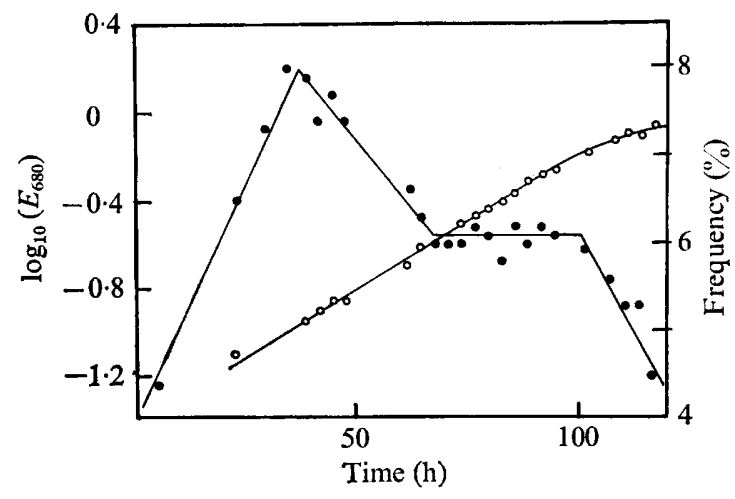

Fig. 3

Fig. 2. Relationship between heterocyst frequency and nitrogenase activity, expressed as a percentage of the final activity, in a differentiated continuous culture of Anabaena cylindrica.

Fig. 3. The change in heterocyst frequency (O), during growth (O), of Anabaena cylindrica on minimal medium in batch culture.

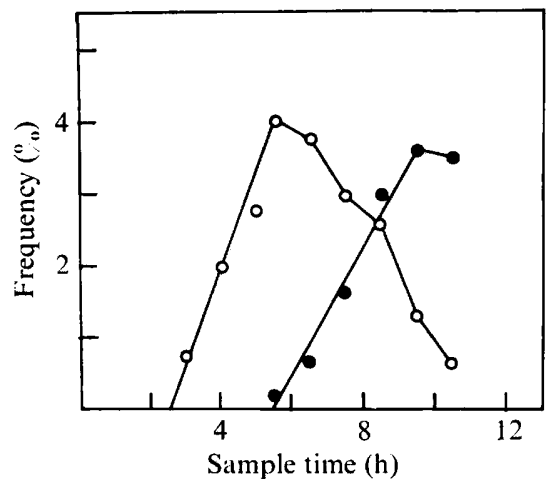

Fig. 4

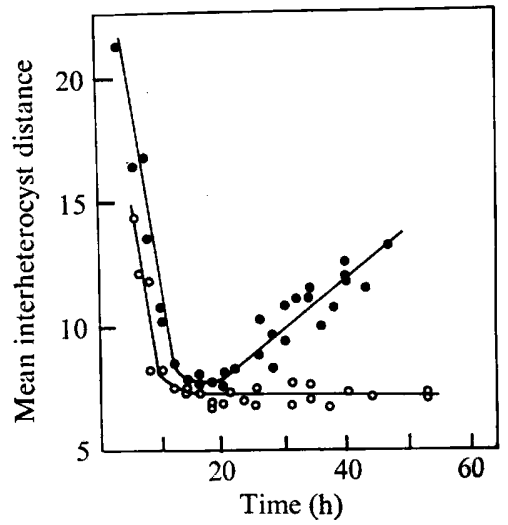

Fig. 5

Fig. 4. Measurement of commitment times in Anabaena cylindrica development. Sample time refers to the period in the absence of ammonium ions. $\bigcirc$, Proheterocysts; $\boldsymbol{\bullet}$, heterocysts.

Fig. 5. The changes in mean interheterocyst distance during differentiation of Anabaena cylindrica under a gas phase of $(\bullet)$ air/carbon dioxide $(95: 5, \mathrm{v} / \mathrm{v}) ;$ and $(\bigcirc)$ argon/carbon dioxide $(95: 5, \mathrm{v} / \mathrm{v})$.

heterocysts, with a maximum frequency of $13 \%$ heterocysts, equivalent to a mean interheterocyst distance of seven to eight cells. In the air/carbon dioxide culture, this value was maintained for some hours before the proportion of heterocysts fell as nitrogen fixation, and hence growth, started. The argon/carbon dioxide culture behaved in an identical manner for the first $20 \mathrm{~h}$, reaching the same maximum heterocyst frequency which was subsequently maintained (Fig. 5). There was no further development of proheterocysts or mature heterocysts in the argon/carbon dioxide culture, even though the culture was acutely nitrogen limited, and presumably the intracellular pools of ammonia, and of metabolically related products, were at a minimum. The involvement of the entire filament in the process of differentiation of some $10 \%$ of its component cells to become heterocysts is illustrated in Fig. 6. The phycocyanin content of the entire filament declined to approximately 10 $\%$ of its 


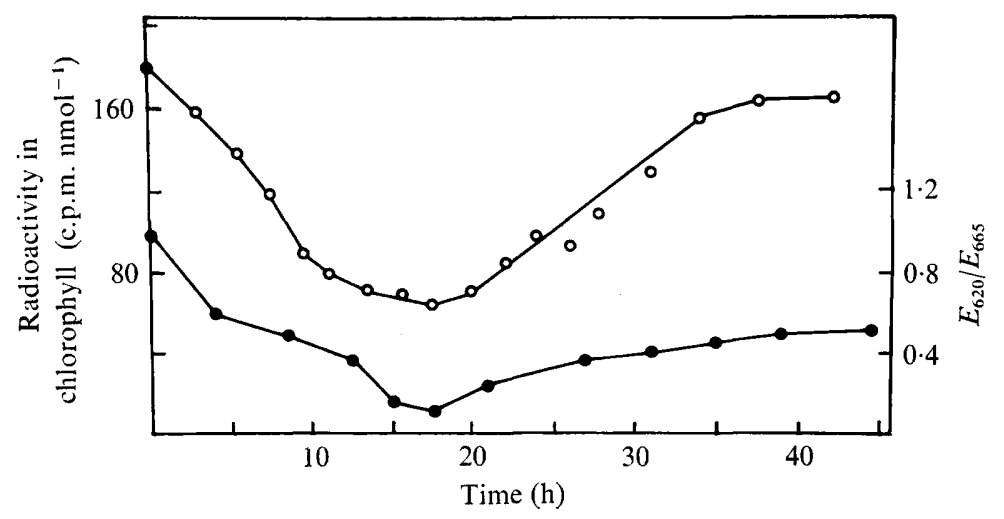

Fig. 6. The changes in light-dependent carbon dioxide fixation $(O)$ and phycocyanin content (๑) during differentiation of Anabaena cylindrica.

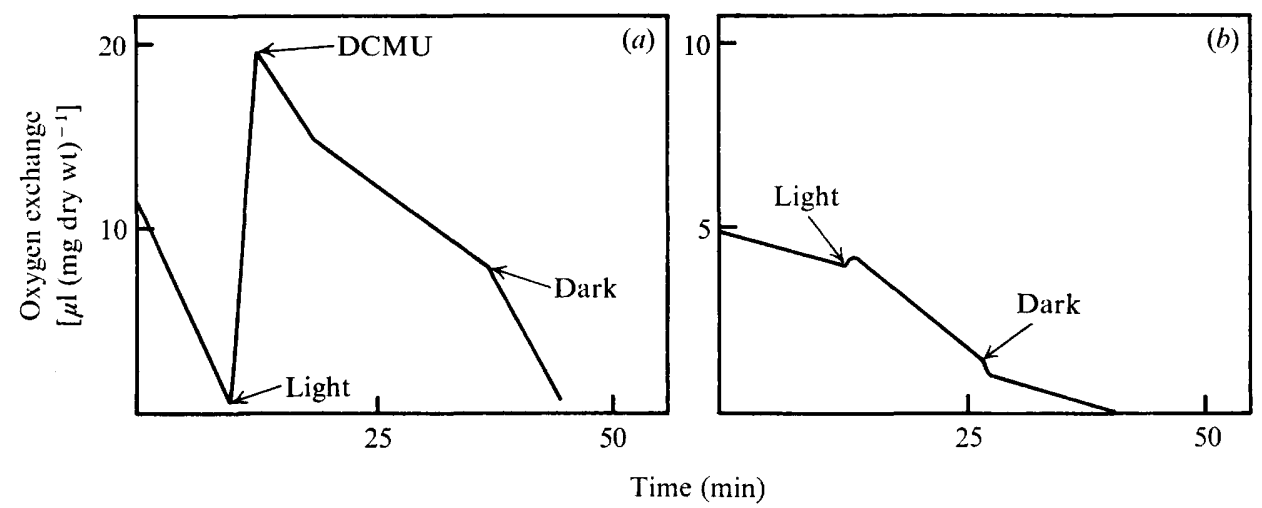

Fig. 7. Oxygen-exchange reactions of $(a)$ intact filaments and $(b)$ isolated heterocysts of Anabaena cylindrica in the light and dark.

value at the time of initiation. The overall rate of carbon dioxide fixation was halved before recovering $20 \mathrm{~h}$ after initiation, at which point nitrogen fixation would also have commenced.

\section{Heterocyst biochemistry}

The accessory photopigment, phycocyanin, is largely absent from heterocysts, and in the blue-green algae this is the major light-harvesting pigment passing energy into photosystem II. There was no evolution of oxygen when a preparation of isolated heterocysts was illuminated with white light, indicating that a functional photosystem II was not present (Fig. 7). This was confirmed by the observation that preparations of heterocysts did not exhibit the delayed fluorescence measured I ms after illumination in a Becquerel-type phosphoroscope.

The respiratory activity of most species of blue-green algae is low, and NADPH, rather than NADH, is the favoured reduced nucleotide for oxidation by extracts (Leach \& Carr, 1968, 1970). Anabaena cylindrica, containing vegetative cells and heterocysts, took up oxygen in the dark $\left[38 \pm 2 \cdot 5\left(\mu \mathrm{O}_{2}\right) \mathrm{h}^{-1}(\mathrm{mg} \mathrm{dry} \mathrm{wt})^{-1}\right]$ at a significantly greater rate than isolated heterocysts $\left[2 \cdot 7 \pm \mathrm{I} \cdot 8\left(\mu 1 \mathrm{O}_{2}\right) \mathrm{h}^{-1}(\mathrm{mg} \mathrm{dry} \mathrm{wt})^{-1}\right]$; both these activities were com- 


\section{Table 2. Nitrogenase activity in intact flaments and isolated heterocysts of Anabaena cylindrica}

Each value is the mean of three determinations.

\begin{tabular}{|c|c|c|}
\hline & \multicolumn{2}{|c|}{ 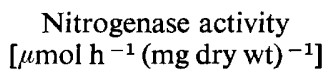 } \\
\hline & Light & Dark \\
\hline Intact filaments & 225 & 38 \\
\hline Isolated heterocysts & $I \cdot 9$ & 0.6 \\
\hline + Phosphoenolpyruvate & $3 \cdot 5$ & $I \cdot O$ \\
\hline+ ATP & $2 \cdot 9$ & 0.5 \\
\hline + DCPIP-ascorbate & $2 \cdot 5$ & 0.4 \\
\hline + Phosphoenolpyruvate and DCPIP-ascorbate & $5 \cdot 7$ & $1 \cdot 3$ \\
\hline
\end{tabular}

pletely inhibited by I mm-potassium cyanide or sodium azide. In contrast, Fay \& Walsby (I966) observed a higher rate of oxygen consumption in the dark in heterocysts than in vegetative cells. Reduced pyridine nucleotide oxidase activities were measured in disrupted heterocysts. Activity was located mainly in the $30000 \mathrm{~g}$ supernatant membrane-containing fraction, which also contained most of the chlorophyll. The level of chlorophyll NADPH oxidase was higher in heterocyst preparations $\left[\mathrm{I} \cdot 6 \pm 0.4 \mu \mathrm{mol} \mathrm{min}^{-1}\right.$ (mg protein) ${ }^{-1}$; three determinations] than in extracts of intact filaments of $A$. cylindrica $\left[0 \cdot 7 \pm 0.2 \mu \mathrm{mol} \mathrm{min}^{-1}\right.$ (mg protein $)^{-1}$; three determinations]. In both preparations, the NADH oxidase activity was considerably less than the NADPH oxidase activity.

Nitrogenase activity was detected in extracts of heterocysts that had been isolated, as far as possible, anaerobically. Under the conditions employed, the nitrogenase activity was directly related to the heterocyst concentration within the range of o to $6 \mathrm{mg}$ dry wt. There was considerable variation in the degree to which nitrogenase survived the heterocyst isolation procedure; under all conditions tested, the nitrogenase activity in isolated heterocysts was very much less than that observed in the intact filaments (approx. I $\%$ to $3 \%$ ). Nitrogenase was more active when the suspension of organisms was illuminated and was stimulated by ATP, dichlorophenolindophenol(DCPIP)-ascorbate and phosphoenolpyruvate (Table 2).

\section{DISCUSSION}

The physiological properties observed in isolated heterocysts of $A$. cylindrica are consistent with the relatively anaerobic conditions necessary for nitrogenase activity. The marked reduction in phycocyanin content (Fay et al., 1968; Thomas, 1970) implies a reduction in photosystem II activity, and the consequent absence of evolved oxygen has been clearly demonstrated (Bradley \& Carr, I97I). In agreement with the results of Donze, Haveman \& Schierek (1972), the delayed fluorescence obtained after subjecting intact $A$. cylindrica filaments to rapid flashes of light was absent from heterocyst preparations. This would indicate a degree of disorganization in the photosystem II apparatus itself rather than a block in the electron-transport chain between photosystem II and photosystem I; an interpretation supported by the low level of $\mathrm{Mn}^{2}+$ found in heterocyst preparations relative to that in vegetative cells (Tel-Or \& Stewart, 1975). There is an anomaly between the low respiration activity of intact heterocyst preparations relative to that of whole filaments, and the observation that NADPH oxidase was greater in extracts of heterocysts than of filaments. 
However, both types of measurement indicate a low rate of oxygen consumption by heterocysts and it is unlikely that this process could contribute significantly to an anaerobic environment for nitrogenase function, as has been suggested for certain heterotrophic nitrogen-fixing bacteria with high rates of oxygen consumption.

The low level of nitrogenase in intact isolated heterocysts showed there was a marked loss of activity during the isolation procedure. Considerable retention of nitrogenase by isolated heterocysts of $A$. cylindrica has been reported by Wolk \& Wojciuch (I97I). The stimulation of nitrogen fixation by the addition to the heterocyst preparation of possible electron donors indicates that the physiological supply of reductant to the enzyme has been disturbed. The increased activity of nitrogenase in the presence of phosphoenolpyruvate may be associated with the presence of pyruvate ferredoxin oxidoreductase in this organism (Bothe \& Falkenberg, 1973). This enzyme catalyses the ATP-activated decarboxylation of pyruvate linked to ferredoxin reduction (Leach \& Carr, 197I) and has been suggested as a possible enzymic source of electrons for nitrogen fixation. Stimulation of nitrogenase in the dark in whole filaments of $A$. cylindrica by pyruvate has been reported by Bennett, Silvester \& Brown (1975), and Codd, Rowell \& Stewart (1974) have demonstrated pyruvate-stimulated acetylene reduction in total extracts (i.e. heterocyst and vegetative cells) of $A$. cylindrica.

The continuous cultures described show that an ordered synthesis of heterocysts can be formed in $A$. cylindrica, although the lack of reduced nitrogen necessary for this to occur also disturbs the continuous culture by arresting further growth until nitrogen fixation begins.

The loss of phycocyanin and the reduction of carbon dioxide fixation are features of heterocyst development and are characteristic of the mature heterocyst. It would appear that at least some biochemical changes develop in all vegetative cells of the filament during the early stages of heterocyst formation, and are reversed after nitrogen fixation has commenced. It has been noted that in Anacystis nidulans, phycocyanin is lost more rapidly than chlorophyll when the nitrogen supply to the organism is curtailed, and so phycocyanin may act as a reserve of amino acids, as well as a light-acceptor (Allen \& Smith, 1969). A similar role in $A$. cylindrica may account for at least some of the decline of phycocyanin in all cells of the filament during the early part of heterocyst development.

After heterocyst development has proceeded for $5.5 \mathrm{~h}$, it cannot be reversed by the readdition of ammonium ions. Commitment to an earlier stage of development occurs more quickly : A. cylindrica produces proheterocysts after only 2 to $3 \mathrm{~h}$ in the absence of ammonium ions. The two parallel graph lines (Fig. 4) leading to different commitment times for different aspects of development are reminiscent of the sequential points of commitment to different stages of spore formation in bacteria. Using a much longer time scale of differentiation, Kulasooriya \& Fay (1974) reported that heterocysts in A. cylindrica were formed only after $24 \mathrm{~h}$ without ammonia. Shorter periods of ammonia-free incubation did not permit heterocyst formation. The fact that a culture of $A$. cylindrica becomes committed to heterocysts after $5.5 \mathrm{~h}$ and that these fully differentiated cells do not appear until approximately $\mathrm{I} 2 \mathrm{~h}$ after initiation indicates some period of delay in the complete expression of the genes responsible for heterocyst production. The absence of heterocysts when cultures of bluegreen algae were grown in the presence of ammonia was observed by Fogg (I949). With the suggestion that heterocysts were the site of nitrogen fixation (Fay et al., I968; Stewart, Haystead \& Pearson, 1969), the idea that ammonium ions, the end-products of that process, were the controlling factors in heterocyst development was strengthened. Ammonium ions have been implicated in the repression of nitrogenase synthesis in several bacteria (Bulen, Burns \& Le Compte, 1964), and they inhibit the activity of existing nitrogenase in bacteria 
(Drozd, Tubb \& Postgate, 1972) but not in blue-green algae (Ohmori \& Hattori, 1972). The experiments described in Fig. 5 argue against ammonium ions, or any other direct product of nitrogen fixation, being the controlling agent in the establishment of the heterocyst pattern in a filament of $A$. cyilindrica. The frequency of heterocyst development is identical under air/carbon dioxide or argon/carbon dioxide conditions up to the stage at which growth recommences. The intracellular pool of any reduced nitrogenase compound must be at a minimum in the argon/carbon dioxide culture from $17 \mathrm{~h}$ onwards, yet no further development of heterocysts (or proheterocysts) occurs.

We interpret this as meaning that the pattern of heterocyst development is a consequence of heterocyst development, and not heterocyst function. At an early stage in development, the cell that is to become a heterocyst establishes on either side a gradient of inhibition that prevents adjacent cells from becoming heterocysts. This gradient is established before nitrogen fixation commences. It is necessary to distinguish between the onset of heterocyst (and nitrogenase) formation, which appears to be controlled by the availability of fixed nitrogen supply (ammonium ions or, to a lesser extent, nitrate), and the subsequent establishment of an ordered sequence of heterocysts down a filament, which results from the formation of zones of inhibition around developing heterocysts. Such a zone of inhibition emanating from proheterocysts has been described by Wilcox et al. (1975) on the basis of direct microscopic observation of heterocyst formation, and these workers have extended the description of heterocyst spacing to include a competitive interaction between the tendency for proheterocyst development and the, as yet, hypothetical inhibitor (Wilcox et al., 1975).

We are indebted to the Science Research Council for support, and acknowledge with thanks the guidance in use of the phosphoroscope in the laboratory of Dr R. P. F. Gregory, University of Manchester.

\section{REFERENCES}

Allen, M. B. \& ARnon, D. I. (1955). Studies on nitrogen-fixing blue-green algae. I. Growth and nitrogen fixation by Anabaena cylindrica. Plant Physiology 30, 366-372.

Allen, M. B. \& Smith, A. J. (1969). Nitrogen chlorosis in blue-green algae. Archiv für Mikrobiologie 69, II4-I 20.

Bennett, K. J., Silvester, W. B. \& Brown, J. M. A. (1975). The effect of pyruvate on nitrogenase activity in the blue-green alga Anabaena cylindrica. Archives of Microbiology 105, 6I-66.

Bothe, H. \& FAlkenberG, B. (1973). Demonstration and possible role of a ferredoxin-dependent pyruvate decarboxylation in the nitrogen fixing blue-green alga Anabaena cylindrica. Plant Science Letters I, I 5 I156.

Bradley, S. \& CARr, N. G. (I97I). The absence of functional photosystem II in heterocysts of Anabaena cylindrica. Journal of General Microbiology 68, xiii-xiv.

Bulen, W. A., Burns, R. C. \& Le Compte, J. R. (1964). Nitrogen fixation : cell free system with extracts of Azotobacter. Biochemical and Biophysical Research Communications 17, 265-27I.

CARR, N. G. \& Bradley, S. (1973). Aspects of development in blue-green algae. Symposium of the Society for General Microbiology 23, I6I-188.

Codd, G. A., Rowell, P. \& Stewart, W. D. P. (1974). Pyruvate and nitrogenase activity in cell-free extracts of the blue-green alga Anabaena cylindrica. Biochemical and Biophysical Research Communications 6r, 424-431.

Donze, M., Haveman, J. \& Schiereck, P. (1972). Absence of photosystem 2 in heterocysts of the blue-green alga Anabaena. Biochimica et biophysica acta 256, I57-I61.

Drozd, J. W., Tubi, R. S. \& Postgate, J. R. (1972). A chemostat study of the effect of fixed nitrogen sources on nitrogen fixation, membranes and free amino acids in Azotobacter chroococcum. Journal of General Microbiology 73, 22 I-232.

FAY, P. (1973). Heterocysts. In The Biology of the Blue-Green Algae, pp. 238-259. Edited by N. G. Carr and B. A. Whitton. Oxford : Blackwells Scientific Publications.

FAY, P. \& WALSBY, A. E. (1966). Metabolic activities of isolated heterocysts of the blue-green alga Anabaena cylindrica. Nature, London 209, 94-95. 
Fay, P., Stewart, W. D. P., Walsby, A. E. \& FogG, G. E. (I968). Is the heterocyst the site of nitrogen fixation in blue-green algae ? Nature, London 220, 81 o-81 2.

FoGG, G. E. (I949). Growth and heterocyst production in Anabaena cylindrica Lemm. II. in relation to carbon and nitrogen metabolism. Annals of Botany, N.S. 13, 24I-259.

ITZHAKI, R. F. \& Gill, D. M. (1964). A micro-biuret method for estimating proteins. Analytical Biochemistry 9, $40 \mathrm{I}-410$.

Kulasooriya, S. A. \& FAY, F. (1974). On the reversibility of heterocyst differentiation. British Journal of Phycology 9, 97-100.

LAYNE, E. (I957). Spectrophotometric and turbidimetric methods for measuring protein. In Methods in Enzymology, vol. I, pp. 447-454. Edited by S. P. Colowick and N. O. Kaplan. New York: Academic Press.

LEACH, C. K. \& CARR, N. G. (I968). Reduced nicotinamide-adenine dinucleotide phosphate oxidase in the autotrophic blue-green alga, Anabaena variabilis. Biochemical Journal ro9, $4 \mathrm{P}-5 \mathrm{P}$.

LEACH, C. K. \& CARR, N. G. (I970). Electron transport and oxidative phosphorylation in the blue-green alga Anabaena variabilis. Journal of General Microbiology 64, 55-70.

LEACH, C. K. \& CARr, N. G. (197I). Pyruvate: ferredoxin oxidoreductase and its activation by ATP in the blue-green alga Anabaena variabilis. Biochimica et biophysica acta 245, 165-I 74.

OHMORI, M. \& HATtoRI, A. (1972). Effect of nitrate on nitrogen fixation by the blue-green alga Anabaena cylindrica. Plant and Cell Physiology $\mathbf{1 3}, 589-599$.

Stewart, W. D. P. \& Lex, M. (1970). Nitrogenase activity in the blue-green alga Plectonema boryanum strain 594. Archiv für Mikrobiologie 73, 250-260.

Stewart, W. D. P., Haystead, A. \& Pearson, H. W. (I969). Nitrogenase activity in heterocysts of bluegreen algae. Nature, London 224, 226-228.

Tel-Or, E. \& Stewart, W. D. P. (I975). Manganese and photosynthetic oxygen evolution by algae. Nature, London 258, 7I5-7I6.

Thомаs, J. (I970). Absence of the pigments of photosystem II of photosynthesis in heterocysts of a bluegreen alga. Nature, London 228, $18 \mathrm{I}-\mathrm{I} 83$.

TydgI, V. V.S. (I975). The heterocysts of blue-green algae (Myxophyceae). Biological Reviews 50, $247-284$.

Vernon, L. P. \& KAMEN, M. D. (1953). Studies in the metabolism of photosynthetic bacteria. XV. Photoautoxidation of ferrocytochrome $c$ in extracts of Rhodospirillum rubrum. Archives of Biochemistry and Biophysics 44, 298-311.

Wilcox, M., Mitchison, G. J. \& SMith, R. J. (1975). Spatial control of differentiation in the blue-green alga Anabaena. In Microbiology-1975, pp. 453-463. Edited by D. Schlessinger. Washington: American Society for Microbiology.

Wolk, C. P. (I975). Differentiation and pattern formation in filamentous blue-green algae. In Spores VI, pp. 85-96. Edited by P. Gerhardt, H. L. Sadoff and R. N. Costilow. Washington: American Society for Microbiology.

Wolk, C. P. \& WoJciuch, E. (I 97I). Photoreduction of acetylene by heterocysts. Planta 97, I $26-134$.

WyATt, J. T. \& SilveY, J. K. G. (I969). Nitrogen fixation by Gloeocapsa. Science, New York 165, 908-909. 